\title{
Preparation of ITO Thin Films by Pulsed Laser Deposition for Use as Transparent Electrodes in Electrochromic Display Devices
}

\author{
Tamiko Ohshima, Takeaki Matsunaga, Hiroharu Kawasaki, Yoshiaki Suda and Yoshihito Yagyu \\ Sasebo National College of Technology, 1-1 Okishin-cho, Sasebo, Nagasaki 857-1193, JAPAN \\ Fax: 81-956-34-8479, e-mail: ohshima@post.cc.sasebo.ac.jp
}

\begin{abstract}
We deposited indium tin oxide (ITO) thin films by pulsed laser deposition (PLD) under various deposition conditions such as different levels of laser fluence and ambient oxygen gas pressure, while maintaining the substrate temperature at room temperature. We investigated the optical, structural, and electrical properties of the films as a function of the deposition conditions. We found that the variation of film properties is more dependent on oxygen gas pressure than on laser fluence. High quality ITO thin films with low electrical resistivity of $2-4 \times 10^{-4} \Omega \cdot \mathrm{cm}$ and high optical transmittance of over $80 \%$ in the visible region are deposited on a glass substrate at room temperature under laser fluence above $4 \mathrm{~J} / \mathrm{cm}^{2}$ and oxygen gas pressure of $1 \mathrm{~Pa}$. We experimentally produced an electrochromic device (ECD) using ITO coated glass substrate deposited at optimal deposition conditions. It is shown that ECD is colored by applied voltage and bleached when the voltage is reversed.

Keywords: transparent conducting oxide, indium tin oxide, electrochromic, pulsed laser deposition
\end{abstract}

\section{INTRODUCTION}

Transparent conducting oxide (TCO) thin films with high transmittance of over $80 \%$ in the visible region and low electrical resistivity of about $10^{-4} \Omega \cdot \mathrm{cm}$ have been used as transparent electrodes in optoelectronic devices such as flat panel displays and solar cells. In particular, indium tin oxide (ITO) has been most widely used for the TCO material and studied extensively using various deposition techniques [1-9].

We have prepared electrochromic devices (ECDs) using tungsten oxide $\left(\mathrm{WO}_{3}\right)$ thin films on the ITO coated flexible substrates at room temperature by pulsed laser deposition (PLD) and RF magnetron sputtering [10]. These ECDs exhibited electrochromic properties, even when the substrates were bent. However these ECDs used commercial flexible substrates coated with the ITO thin films and aqueous electrolyte. Development of all-solid-state ECDs with high durability of materials is required in the future.

In this study, we prepared the ITO thin films on flexible substrates at room temperature by the PLD method; these films are used as transparent electrodes in all-solid-state ECDs. In addition, to study the effect of deposition conditions on film properties, we performed optical emission spectroscopy (OES) of a plasma plume produced during deposition of the ITO thin films.

\section{EXPERIMENTAL}

The PLD system consisted of a vacuum chamber with vacuum pumps (an oil-free scroll pump and a turbo molecular pump) and a second harmonic $(\lambda=532 \mathrm{~nm})$ Nd:YAG laser (Continuum, Surelite III-10). The base pressure in the vacuum chamber was $5 \times 10^{-5} \mathrm{~Pa}$; ambient oxygen gas was introduced into the chamber through a mass flow controller. Indium tin complex oxide (Kojundo Chemical Laboratory, 95 wt $\% \operatorname{In}_{2} \mathrm{O}_{3}-5$ wt $\% \mathrm{SnO}_{2}$, purity $99.99 \%$ ) was used as a target. The substrates of $\mathrm{SiO}_{2}$ glass and $\mathrm{Si}(100)$ were cleaned with distilled water and acetone before use. The target-to-substrate distance was about $5 \mathrm{~cm}$. The laser beam was focused on a $0.8-1.8 \mathrm{~mm}^{2}$ elliptical spot at the target surface using a focal lens. The laser radiation was introduced at $45^{\circ}$ with respect to the target surface. ITO thin films were deposited under different laser fluences $\left(\mathrm{E}_{\mathrm{L}}\right)$ ranging from 2 to $6 \mathrm{~J} / \mathrm{cm}^{2}$ and oxygen gas pressures $\left(\mathrm{P}_{\mathrm{O} 2}\right)$ ranging from vacuum to $100 \mathrm{~Pa}$, while maintaining the substrate temperature at room temperature (RT). The depositions were performed for 5-45 min.

Optical transmittance of the ITO thin films was measured using a UV-VIS optical spectrophotometer (Shimadzu, UVmini-1240). The electrical properties were measured using a four-point probe resistivity meter (Mitsubishi Chemical, MCP-T610). The structural properties were measured using an X-ray diffractometer (XRD; Rigaku, RINT-2100VSK). The thickness of the films was determined using a surface profiler (Veeco, Dektak 3).

The light emitted from the laser induced plasma plume was measured using a spectrometer (Hamamatsu Photonics, C5095) equipped with an ICCD camera (Hamamatsu Photonics, C7164-03) by varying the distance from the target surface.

\section{RESULTS AND DISCUSSION}

3.1 Studies of the plasma plume

Figure 1 shows the optical emission spectra of the ITO ablation plume at (a) $x=0, y=0.5 \mathrm{~mm}$ and (b) $x=$ $y=2 \mathrm{~mm}$ from the target surface. The inset of Fig. 1 (b) shows a photograph of the plasma plume and the positions of OES measurement. The intense peaks of Fig. 1 (a) and (b) are identified with atomic species (In I, Sn I, and O I). The emission intensity of In I (451 nm) and O I $(777 \mathrm{~nm})$ lines detected at $0.5 \mathrm{~mm}$ from the target surface kept constant regardless of the variation of the 
oxygen gas pressure. The emission intensity of these lines observed in a position at $2 \mathrm{~mm}$ from the surface of the target increased with increasing the oxygen gas pressure. In particular, the $\mathrm{O}$ I intensity of $10 \mathrm{~Pa}$ was 10 times larger than that of $1 \mathrm{~Pa}$. This difference between the intensity of emission lines and the variation of the oxygen gas pressure affected to create oxygen vacancies as an electron carrier source in the ITO thin films.

The ionic In species (In II) at 468 and $488 \mathrm{~nm}$ shown in Fig. 1 (a) and (b) are detected. Other ionic species ( $\mathrm{Sn}$ II, O II) shown in Fig. 1 (a) are also detected near the target surface; these species are difficult to detect at a position away from the target, as shown in Fig. 1 (b). The following are the processes involved in a PLD method: (i) ejection of species with high kinetic energy near the target surface immediately after laser irradiation; (ii) formation of the plasma plume; and (iii) expansion of the plume in ambient gas [11].

\subsection{The deposition rate of ITO films in a wide range of $\mathbf{P}_{\mathrm{O} 2}$}

Figure 2 shows the variation of the deposition rate of the ITO thin films, deposited at a wide range of $\mathrm{P}_{\mathrm{O} 2}$, from the base pressure to $100 \mathrm{~Pa}$. The deposition rate increases up to $\mathrm{P}_{\mathrm{O} 2}$ of $10-20 \mathrm{~Pa}$ and then decreases at high $\mathrm{P}_{\mathrm{O} 2}$. In the low range of $\mathrm{P}_{\mathrm{O} 2}$, from $0.1 \mathrm{~Pa}$ and below, the shape of the plasma plume was not distinct, because ablation particles from the target surface by laser irradiation were not colliding with the ambient gas molecules. As a result, the ablation particles dispersed
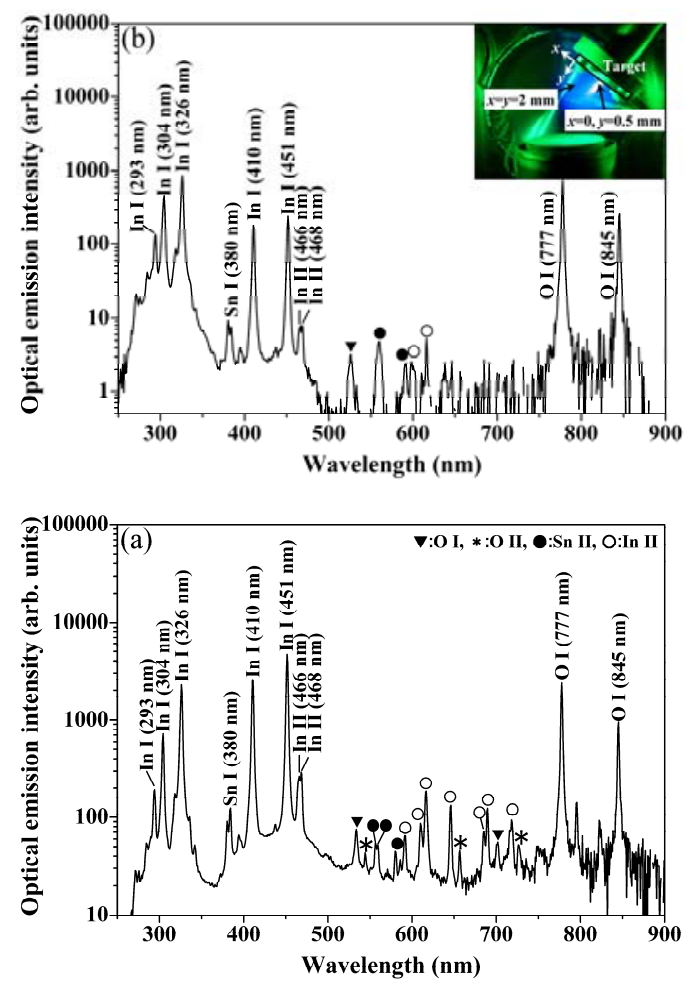

Fig.1 Emission spectra of plasma plume at (a) $x=0, y=0.5 \mathrm{~mm}$ and (b) $x=y=2 \mathrm{~mm}$ from target surface at $\mathrm{P}_{\mathrm{O} 2}=10 \mathrm{~Pa}$ and $\mathrm{E}_{\mathrm{L}}=4 \mathrm{~J} / \mathrm{cm}^{2}$. and were not deposited on the substrate. In the middle range of $\mathrm{P}_{\mathrm{O} 2}$, from 1 to $20 \mathrm{~Pa}$, the shape of the plasma plume could be observed clearly. At $\mathrm{P}_{\mathrm{O} 2}$ of $10 \mathrm{~Pa}$ and above, the plasma plume with distinct boundary was formed, and the tip of the plasma plume emitted intensively. This was due to reactions such as collisions between the plasma plume and ambient gas molecules. The progress distance of the plasma plume was about the same as the target-to-substrate distance; consequently, the thickness of the film deposited on the substrate increased more than that of the films deposited at low $\mathrm{P}_{\mathrm{O} 2}$. In the high $\mathrm{P}_{\mathrm{O} 2}$ range, from $50 \mathrm{~Pa}$ and above, the kinetic energy of the plasma plume was lost because of less-intensive collisions between the plasma plume and the ambient gas molecules. It was difficult for the plasma plume to reach the substrate, and therefore the thickness of the deposited film decreased.

\subsection{Properties of ITO films deposited under high $\mathbf{P}_{\mathrm{O} 2}$}

Figure 3 shows the optical transmission spectra of ITO thin films deposited at $\mathrm{E}_{\mathrm{L}}=4 \mathrm{~J} / \mathrm{cm}^{2}$ and $\mathrm{P}_{\mathrm{O} 2}=1,5$, 10,50 , and $100 \mathrm{~Pa}$. At $\mathrm{P}_{\mathrm{O} 2} \leq 50 \mathrm{~Pa}$, the ITO films with transmittance above $80 \%$ in the visible region were obtained, whereas the film deposited at $\mathrm{P}_{\mathrm{O} 2}=100 \mathrm{~Pa}$ was whitish in color and less transparent.

Figure 4 shows the average transmittance in the visible region of $380-780 \mathrm{~nm}$ and the electrical

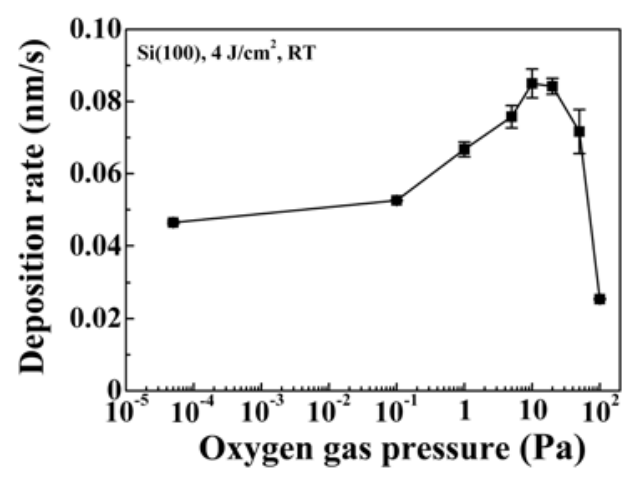

Fig.2 Dependence of $\mathrm{P}_{\mathrm{O} 2}$ on deposition rates of ITO thin films.

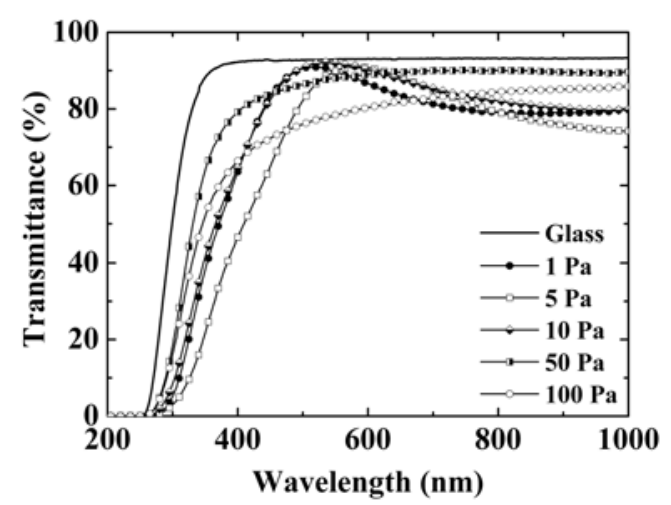

Fig. 3 Optical transmission spectra of ITO thin films deposited at various $\mathrm{P}_{\mathrm{O} 2}$. 
resistivity of the ITO thin films. The optical and electrical properties of the ITO films are also dependent on $\mathrm{P}_{\mathrm{O} 2}$. High transmittance (above $80 \%$ ) and low resistivity $\left(3.6 \times 10^{-4} \Omega \cdot \mathrm{cm}\right)$ were obtained in the film deposited at $\mathrm{E}_{\mathrm{L}}=4 \mathrm{~J} / \mathrm{cm}^{2}$ and $\mathrm{P}_{\mathrm{O} 2}=1 \mathrm{~Pa}$.

\subsection{Properties of ITO films deposited under low $P_{02}$}

ITO thin films were deposited at $\mathrm{E}_{\mathrm{L}}=2,4$, and 6 $\mathrm{J} / \mathrm{cm}^{2}$ and comparatively low $\mathrm{P}_{\mathrm{O} 2}$ values of vacuum (base pressure $=5 \times 10^{-5} \mathrm{~Pa}$ ), $0.1,1,5,10$, and $20 \mathrm{~Pa}$, because we investigated the characteristics of the films deposited under and around $\mathrm{P}_{\mathrm{O} 2}=1 \mathrm{~Pa}$ in detail.

Figure 5 shows the optical and electrical properties of the ITO thin films referred to in Fig. 3. The average transmittance in the visible region improves as $\mathrm{P}_{\mathrm{O} 2}$ increases. We obtained the films deposited at $\mathrm{E}_{\mathrm{L}} \geq 4$ $\mathrm{J} / \mathrm{cm}^{2}$ and $\mathrm{P}_{\mathrm{O} 2} \geq 1 \mathrm{~Pa}$ with a high transmittance of above $80 \%$.

Figure 6 shows the XRD patterns of the ITO thin films deposited at $E_{L}=4 \mathrm{~J} / \mathrm{cm}^{2}$ and with increasing $\mathrm{P}_{\mathrm{O} 2}$. Amorphous ITO films were obtained at $\mathrm{P}_{\mathrm{O}_{2}} \leq 5 \mathrm{~Pa}$; and small peaks of (222), (440), and (622) corresponding to the $\mathrm{In}_{2} \mathrm{O}_{3}$ cubic crystalline structure appear at $\mathrm{P}_{\mathrm{O} 2} \geq 10$ $\mathrm{Pa}$. The broad peaks around $2 \theta=30-35^{\circ}$ indicate that the films have a mixed amorphous and crystalline phase with (222) and (400) diffraction peaks. Therefore, preferable ITO thin films deposited at $\mathrm{E}_{\mathrm{L}} \geq 4 \mathrm{~J} / \mathrm{cm}^{2}$ and $\mathrm{P}_{\mathrm{O} 2}=1 \mathrm{~Pa}$, as shown in Fig. 5, exhibit non-crystalline amorphous nature. However, for application as transparent electrodes in ECDs, the ITO films of crystalline nature are preferred.

\subsection{The effect of thickness}

We have prepared ITO thin films at $\mathrm{E}_{\mathrm{L}}=4 \mathrm{~J} / \mathrm{cm}^{2}$ and $\mathrm{P}_{\mathrm{O} 2}=1 \mathrm{~Pa}$, while increasing the deposition time. Thicknesses of the ITO films obtained were 20, 59, 131, and $167 \mathrm{~nm}$ at the deposition times of 5, 15, 30, and 45 min, respectively.

Figure 7 shows the XRD patterns of the ITO thin films deposited with increasing thickness. The ITO thin films below $59 \mathrm{~nm}$ exhibit an amorphous nature and are similar to the XRD result shown in Fig. 4. The thickness of the ITO film deposited at $\mathrm{E}_{\mathrm{L}}=4 \mathrm{~J} / \mathrm{cm}^{2}, \mathrm{P}_{\mathrm{O} 2}=1 \mathrm{~Pa}$ for the deposition time of $10 \mathrm{~min}$, as shown in Fig. 4, was

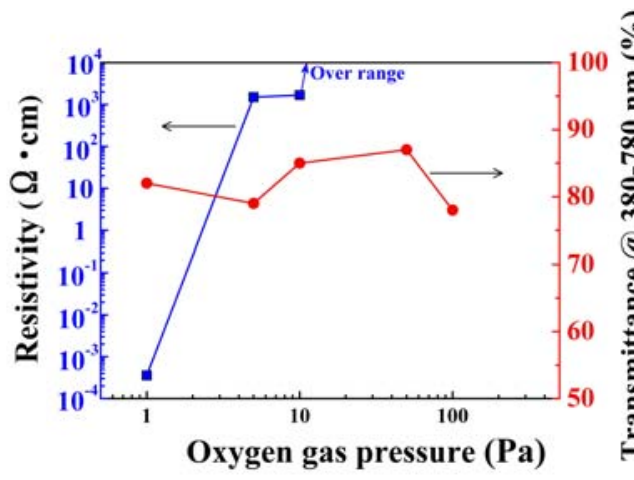

Fig.4 Variation of average transmittance in visible region $(\bullet)$ and electrical resistivity ( $\bullet$ ) as a function of $\mathrm{P}_{\mathrm{O} 2}$ for ITO thin films deposited at $\mathrm{E}_{\mathrm{L}}=4 \mathrm{~J} / \mathrm{cm}^{2}$.
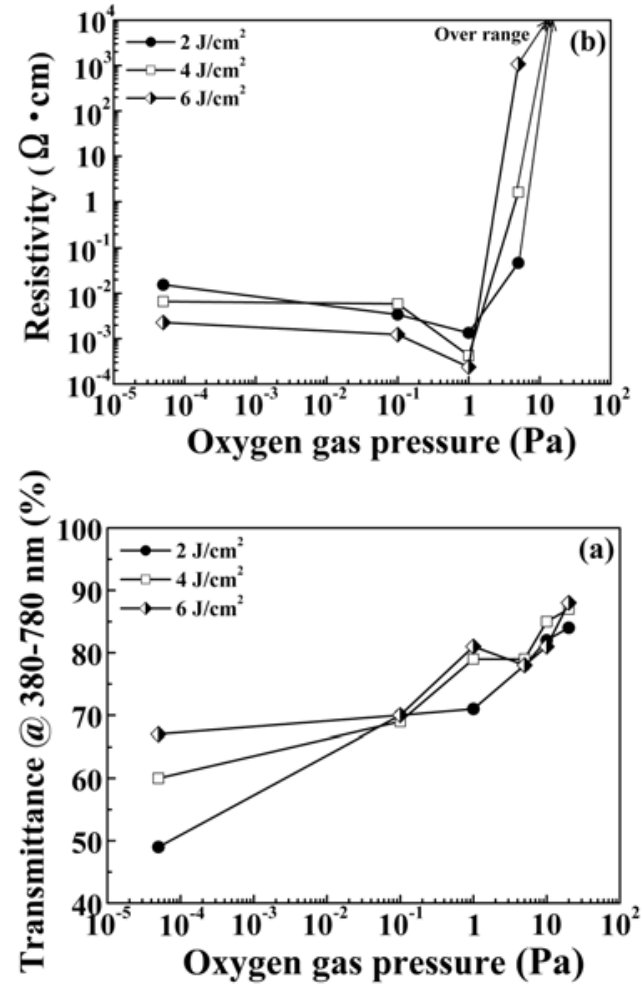

Fig.5 Variation of (a) average transmittance in visible region and (b) electrical resistivity as a function of $\mathrm{P}_{\mathrm{O} 2}$ for ITO films deposited at $\mathrm{E}_{\mathrm{L}}=2,4$, and $6 \mathrm{~J} / \mathrm{cm}^{2}$.

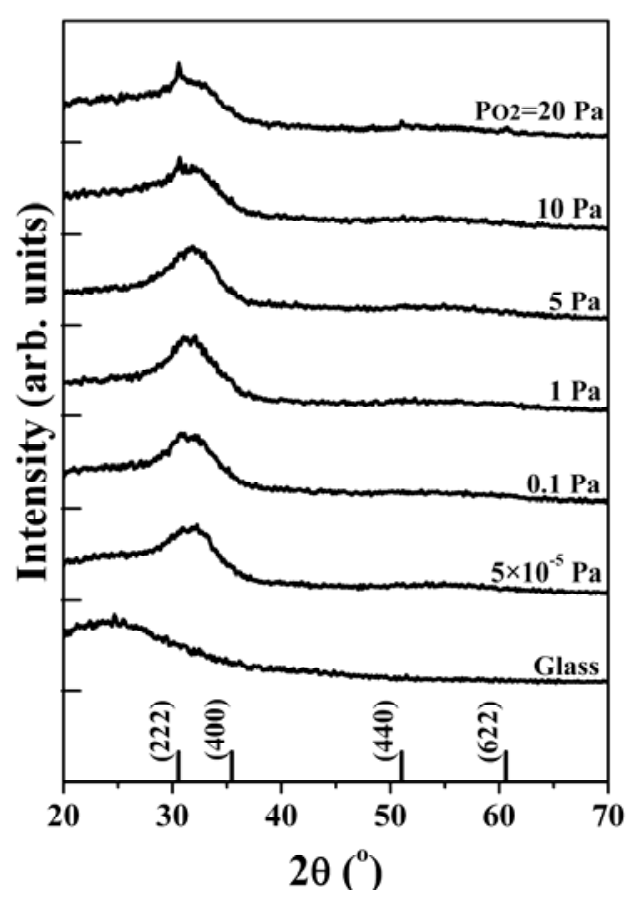

Fig. 6 XRD patterns of ITO thin films deposited at $\mathrm{E}_{\mathrm{L}}=4 \mathrm{~J} / \mathrm{cm}^{2}$ and with increasing $\mathrm{P}_{\mathrm{O} 2}=5 \times$ $10^{-5}$ (vacuum), $0.1,1,5,10$, and $20 \mathrm{~Pa}$. 
estimated to be $42 \mathrm{~nm}$. The increase of the thickness to more than $59 \mathrm{~nm}$ leads to improved crystallinity.

Figure 8 shows the relationship between the electrical resistivity and the thickness of the ITO thin films. The resistivity of the ITO films is found to decrease with increasing thickness; the minimum resistivity achieved is $2.9 \times 10^{-4} \Omega \cdot \mathrm{cm}$ for the film deposited at $167 \mathrm{~nm}$.

Figure 9 shows the optical transmittance spectra of the ITO thin films with different thicknesses. The transmittance in the visible region slightly decreases and an absorption edge gradually shifts to longer wavelengths (redshift) as the thickness of the ITO films

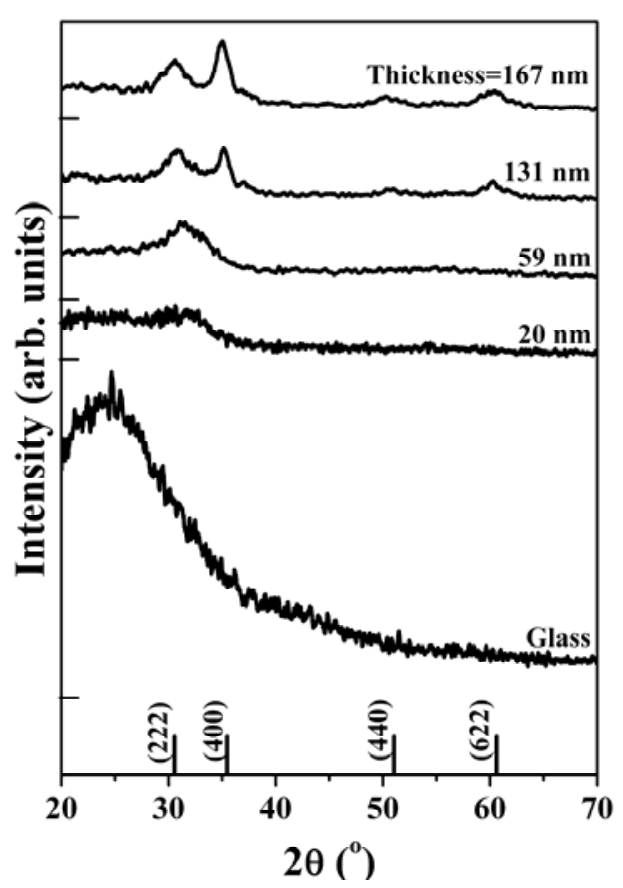

Fig. 7 XRD patterns of ITO thin films deposited at $\mathrm{E}_{\mathrm{L}}=4 \mathrm{~J} / \mathrm{cm}^{2}, \mathrm{P}_{\mathrm{O} 2}=1 \mathrm{~Pa}$ and with increasing thicknesses of $20,59,131$, and $167 \mathrm{~nm}$.

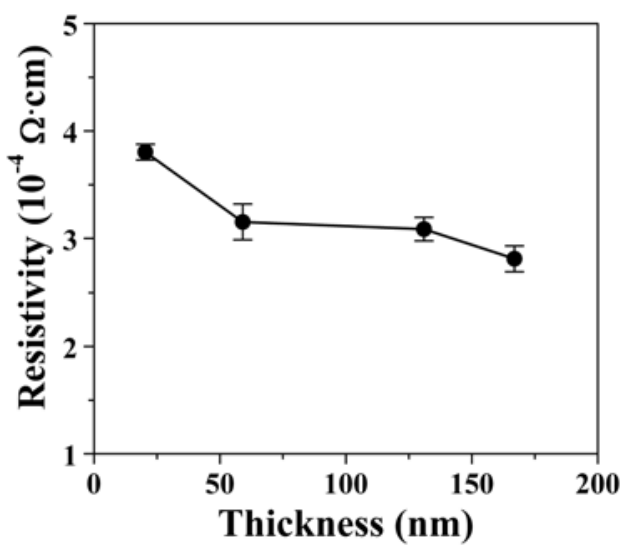

Fig. 8 Variation of electrical resistivity of ITO thin films with different thicknesses. increases. The inset shows an optical band gap $E_{\mathrm{g}}$ of the ITO films, which can be estimated from the Tauc relation given by

$\alpha h v=A\left(h v-E_{g}\right)^{1 / 2}$,

where $\alpha$ is an absorption coefficient, $h v$ is a photon energy, $A$ is a constant, and $E_{g}$ is the optical band gap

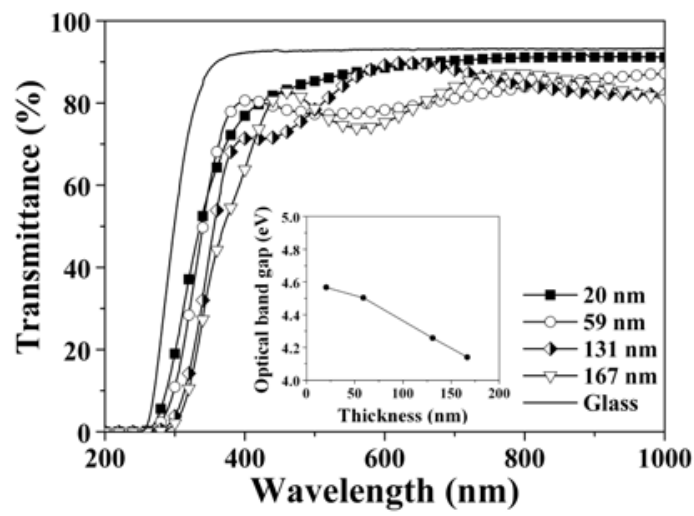

Fig.9 Optical transmittance spectra of ITO thin films with different thicknesses. Inset shows optical band gap estimated from Tauc's plot.

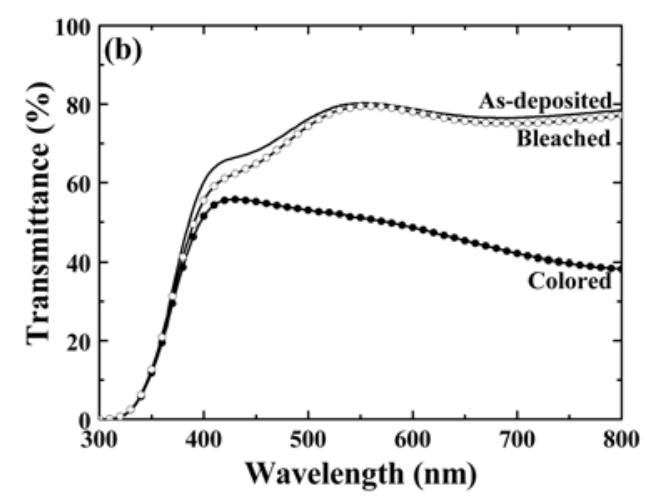

(a)

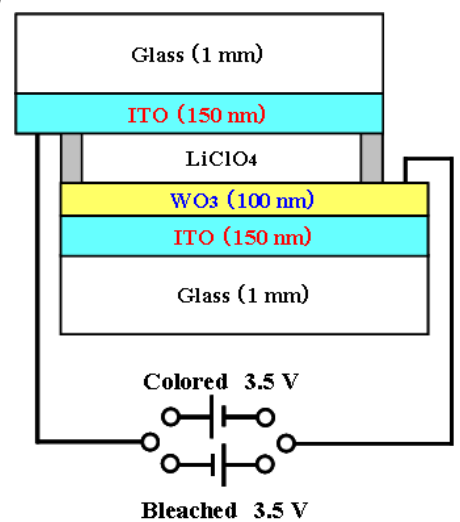

Fig.10 Electrochromic properties of (a) schematic layer structure of ECD (size $2 \times 2$ $\mathrm{cm}^{2}$ ) and (b) optical transmittance spectra of ECD in colored and bleached states. 
[12]. The optical band gap was obtained from the intercept of $(\alpha h v)^{2}$ versus $h v$ for direct allowed transitions. The values of $E_{g}$ decrease with increasing thickness of the ITO films.

\subsection{Electrochromic property}

ITO thin films with better properties, i.e., low resistivity, high transparency, and crystalline nature could be prepared at optimal deposition conditions $\left(\mathrm{E}_{\mathrm{L}}=\right.$ $4 \mathrm{~J} / \mathrm{cm}^{2}, \mathrm{P}_{\mathrm{O} 2}=1 \mathrm{~Pa}$ ) and at thickness $\geq 131 \mathrm{~nm}$.

Figure 10 (a) shows the fabrication of an electrochromic device (ECD) that is composed of 150-nm-thick ITO thin films as the transparent electrodes and a 100 -nm-thick $\mathrm{WO}_{3}$ thin film (deposited using RF magnetron sputtering) as the electrochromic layer. A $1 \mathrm{~mol} / \mathrm{L} \mathrm{LiClO}_{4}$ (Kishida Chemical) aqueous solution is used as the electrolyte. Figure 10 (b) shows the visible transmittance spectra of ECD in colored and bleached states under applied voltage. The color of the ECD changed from transparent to blue after applying the voltage of $\pm 3.5 \mathrm{~V}$ and changed again from blue to transparent after applying a reverse voltage.

\section{CONCLUSIONS}

We prepared ITO thin films by PLD at various levels of laser fluence and ambient oxygen gas pressure, while maintaining the substrate temperature at room temperature. We found the optical, electrical, and structural properties to be influenced by the oxygen gas pressure. ITO thin films with better properties, i.e., low electrical resistivity of $2-4 \times 10^{-4} \Omega^{\cdot} \mathrm{cm}$ and high optical transmittance of over $80 \%$ in the visible region were obtained under laser fluence of above $4 \mathrm{~J} / \mathrm{cm}^{2}$ and oxygen gas pressure of $1 \mathrm{~Pa}$ at room temperature. An amorphous to crystalline transition was observed when increasing the thickness of the ITO thin films; the films with a polycrystalline phase were obtained at a thickness $\geq 131 \mathrm{~nm}$. An ECD $\left(\right.$ size $\left.2 \times 2 \mathrm{~cm}^{2}\right)$ fabricated by ITO electrode films deposited at optimal conditions $\left(\mathrm{E}_{\mathrm{L}}=4\right.$ $\mathrm{J} / \mathrm{cm}^{2}, \mathrm{P}_{\mathrm{O} 2}=1 \mathrm{~Pa}$, and thickness $=150 \mathrm{~nm}$ ) showed colored and bleached states by applying voltage.

\section{References}

[1] H.R. Fallah, M. Ghasemi, A. Hassanzadeh and H. Steki, Physica B, 373, 274-79 (2006).

[2] A.M.E. Raj, K.C. Lalithambika, V.S. Vidhya, G. Rajagopal, A. Thayumanavan, M. Jayachandran and C. Sanjeeviraja, Physica B, 403, 544-54 (2008).

[3] D.F. Lii, J.L. Huang, I.J. Jen, S.S Lin and P. Sajgalik, Surf. Coat. Tech., 192, 106-11 (2005).

[4] C. Guillén and J. Herrero, Thin Solid Films, 480-481, 192-32 (2005).

[5] V.Malathy, S. Sivaranjani, V.S. Vidhya, J.J Prince, T. Balasubramanian, C. Sanjeeviraja and M. Jayachandran, J. Non-Cryst. Solods, 355, 1508-16 (2009).

[6] F.O. Adurodija, H. Izumi, T. Ishihara, H. Yoshioka, H. Matsui and M. Motoyama, Vacuum, 59, 641-48 (2000).

[7] S.H. Kim, N.M. Park, T.Y. Kim and G.Y. Sung, Thin Solid Films, 475, 262-66 (2005).

[8] Z.Z. You, J. Elec. Spec. Relat. Phenom., 160, 29-34 (2007).

[9] M.G. Sandoval-Paz and R. Ramírez-Bon, Thin Solid Films, 517, 2596-601 (2009).
[10] Y. Suda, H. Kawasaki, T. Ohshima and Y. Yagyuu, Thin Solid Films, 516, 13, 4397-401 (2008).

[11] R.K. Thareja, R.K. Dwivedi and K. Ebihara, Nucl. Instrum. Methods Phys. Res. B, 192, 301-10 (2002).

[12] J. Tauc, R. Grigorovici, A. Vancu, Phys. Stat. Sol., 15, 627-37 (1966).

(Received December 31, 2009; Accepted July 11, 2010) 